\title{
Molecular Cloning, Developmental Expression, and Hormonal Regulation of Zebrafish (Danio rerio) $\beta$ Crystallin B1, a Member of the Superfamily of $\beta$ Crystallin Proteins
}

\author{
J yh-Yih Chen,* Bei-En Chang, $†$ Yi-Hsuan Chen, $\neq$ Cliff J i-Fan Lin,* \\ $\mathrm{J}$ en-Leih $\mathrm{Wu},{ }^{*} \neq^{\prime 1}$ and Ching-Ming Kuos, ${ }^{2}$ \\ *Institute of Zoology, Academia Sinica, Nankang, Taipe, Taiwan, Republic of China; †Graduate Institute of Oral Biology, \\ College of Medicine, and ¥I nstitute of Fisheries Science, National Taiwan University, Taipei, Tai wan, Republic of China; \\ and §Department of Aquaculture, National Ping-Tung Technology University, Taiwan, Republic of China
}

The cDNA sequence of $\beta$ crystallin B1 was determined from zebrafish (Danio rerio) and compared to the corresponding genes of bovine, rat, chicken, human, and Xenopus. Multispecies comparison of superfamily diversity demonstrated $\beta$ crystallin B 1 homology between zebrafish, bovine, chicken, and rat, but large distances to $\beta$ crystallin B2 and B3. Zebrafish CDNA has a size of 943 nucleotides and encodes a polypeptide of $\mathbf{2 3 3}$ amino acids. Zebrafish $\beta$ crystallin B 1 shares $71.30,75.86$, and $71.00 \%$ similarities with bovine, chicken, and rat $\beta$ crystallin B1, respectively. Northern blot analysis revealed a single 0.9-kb $\beta$ crystallin B1 transcript which was expressed and progressively increased in the first $20 \mathrm{~h}$ of zebrafish embryogenesis. Whole-mount in situ hybridization revealed that the $\beta$ crystallin B1 transcript was only specifically expressed in the lens region of the eye. A starvation experiment revealed no variation in MRNA levels after 14 and 21 days. An experiment in which hormone was injected showed that the $\beta$ crystallin B1 transcript first increased $\mathbf{2 4} \mathrm{h}$ after the injection of insulin-like growth factor I, insulin-like growth factor II, or growth hormone, then decreased $48 \mathrm{~h}$ after injection. The $\beta$ crystallin B1 transcript continuously increased after insulin was injected. Taken together, our results identify the early specific expression of $\beta$ crystallin B1 within the lens. Despite small differences, these results indicate that both the structure of the $\beta$ crystallin $B 1$ protein and its involvement with regulation by

\footnotetext{
${ }^{1}$ To whom correspondence and reprint requests may be addressed at Laboratory of Marine Molecular Biology and Biotechnology, Institute of Zoology, Academia Sinica, Nankang, Taipei, Taiwan 115, Republic of China. Fax: 886-227824595. E-mail: zojlwu@ccvax.sinica. edu.tw.

${ }^{2}$ To whom correspondence and reprint requests may be addressed. Fax: 886-87740344. E-mail: cmkuo@mail.npust.edu.tw.
}

growth factors appear to have been remarkably conserved. ๑ 2001 Academic Press

Key Words: zebrafish; $\beta$ crystallin B1; insulin-like growth factor; insulin; growth hormone; starvation; in situ hybridization.

The developing lens of zebrafish is an excellent model system for the study of many fundamental morphogenetic processes occurring during embryonic devel opment (1). The structure of the lens contains familiar cytoskeletal and other proteins; the major part of the macromolecular constituents are soluble proteins of crystallins. The crystallins comprise an $\alpha$ crystallin family and the $\beta / \gamma$ crystallin superfamily. A Crystallin, $\beta$ crystallin, and $\gamma$ crystallin are specialized lens proteins, each the product of genes that may have formed from duplication and divergent evolution from the same ancestors with different functions (2). The present report concerns the $\beta$ crystallin B1 gene of the zebrafish. Since most of a fish's lens in the water is in direct contact with environmental factors (e.g., toxins, nutritional factors, aquatic bacteria, and viruses), cataracts may form easily. One of hopothesis for the prevalence of cataracts with age is that the chaperone capacity of $\alpha$ crystallin becomes exhausted with time (3). However, $\beta$ crystallins are expressed in both mitotically active and anterior epithelial cells in the chicken (4). $\beta$ crystallin B 1 first appear in el ongating equatorial cells of the lens and accumulates in nondividing, posterior fiber cells (5). Little is known about how insulin, IGF-I, IGF-II, and GH affect the protein composition of the lens fiber cells with possible consequences of cataracts. To address this question at the molecular level, major lens structural proteins such as crystallins are 
being studied. They are not only abundantly synthesized during various steps of embryogenesis but also are expressed in a region-specific manner in the lens. The $\beta$ - and $\gamma$-crystallins are found only in fiber cells; their mRNAs appear and accumulate sequentially during the course of in vitro and in vivo differentiation (6-8). It is useful in in vitro fiber cell differentiation studies to use $\beta$ and $\gamma$ crystallins as markers. The fiber differentiation response can induce and specifically respond to FGF, but it also modulates a differentiation response in other growth factors. In vitro differentiation of rat lens explants with the addition of both insulin and FGF-2 resulted in a six-fold increase in the ratio of $\gamma$ crystallin to $\beta$ crystallin over that found when only FGF-2 was added (9). In the presence of FGF-2, IGF-I or insulin will synergistically enhance both the differentiation and proliferation responses; but only proliferation occurs in the absence of FGF-2 $(10,11)$. These effects appear to be mediated through the I GF-I receptor. Under the background described above, we attempted to identity zebrafish $\beta$ crystallin B1 CDNA, as well as its specific expression in developmental stages, and hormonal regulation of $\beta$ crystallin B1. mRNA hybridization data imply an identical primary transcript at $20 \mathrm{hpf}$. Whole-mount in situ hybridization data show $\beta$ crystallin B1-specific expression in the lens region. To prove whether growth factor regulation is involved in $\beta$ crystallin B1 gene expression, we used real-time quantitative PCR to address the question. It appears from our results that growth factor-dependent expression will affect $\beta$ crystallin B1 expression.

\section{MATERIALS AND METHODS}

Isolation of zebrafish $\beta$ crystallin B1 CDNA clones and sequence analysis. PCR primers for cloning $\beta$ crystallin B1 CDNA are located on conserved coding regions. PCR primers (Quality Systems, Taiwan and Mdbio, Taiwan) were designed based upon the comparison results of $\beta$ crystallin B1. CRQ1 primer, 5'-GATGGAGGTCCAGAATGAGT; CRQ2 primer, 5'-GGAATGGACAGAGTCCGCAG; CRP1 primer, 5'-CGGGGTGGGAGTGCGACGGG; CRP2 primer, 5'-ACTCTGTCGCAGAAACCGTG; CRP3 primer, 5'-CGCCCACAGGGTTGGCACAT. Real-time quantitative PCR primers, 5'-ATGTCTCAGACCGCCAAATCCGC; 5'-CCTGGTCAAACAGGAAGATTTTG. A zebrafish heart cDNA library and a zebrafish 24-h embryo cDNA library were used as a template to amplify internal fragments as a screening CDNA library probe. The PCR reaction was carried out in a final volume of $100 \mu \mathrm{L}$. The reaction consisted of the CDNA library liquids, $10 \mu \mathrm{L}$ of $10 \times$ PCR buffer (HT Biotechnology, U.S.A.), $200 \mu \mathrm{M}$ of each dNTP, $1 \mu \mathrm{g}$ of the IGFBP and HDLBP forward and reverse primers, and 2.5 units of Taq DNA polymerase. The reaction and process followed those we published before (12-15). The PCR product was purified by electroelution and used as a probe for isolating 1 million clones from a zebrafish heart CDNA library and a zebrafish 24-h embryo cDNA library by the plaque hybridization method, as we published previously (12-15). $\beta$ crystallin B1 cDNA was analyzed with an automated Applied Biosystem 373A Genetic Analysis System. Nucleotides and the resulting translation sequences were aligned and compared using the PILEUP and GAP programs (Genetics Computer Group), respectively.
RNA isolation and quantification of mRNA using real-time reverse transcription polymerase reaction assays. Starvation and hormonal treatment of gene regulation affected variations in mRNA levels. Each 0.4-g zebrafish was injected intraperitoneally with $1 \mu \mathrm{g} \mathrm{IGF-I}$ or $1 \mu \mathrm{g} \mathrm{IGF-II} \mathrm{or} 1 \mu \mathrm{g} \mathrm{GH}$ or $1000 \mu \mathrm{g}$ insulin. After the injection, we extracted total RNA at different times. Total RNA was isolated from the starvation-treated and hormone-regulated zebrafish following the manufacturer's protocols (ULTRASPECTM-II RNA isolation system; Biotecx Laboratories, U.S.A.). Each group was replicated three times. Total RNA at $5 \mu \mathrm{g}$ was transcribed as first-strand CDNA by a random primer for the hormone regulation and starvation experiments. Real-time quantitative PCR produced values which represent an arbitrary unit defined as real-time quantitative PCR analysis of $\beta$ crystallin B1 and $\beta$-actin transcripts from different fish. Five micrograms of total RNA was isolated from each tissue and transcribed to $50 \mu \mathrm{L}$ of first strand CDNA; $1 \mu \mathrm{L}$ of first strand CDNA and $1 \mu \mathrm{g}$ of each primer were used to run real-time quantitative PCR. An $18-\mu l$ volume was loaded into the glass microcapillary reaction vessels. The CDNA was denatured by heating to $96^{\circ} \mathrm{C}$ for $1 \mathrm{~min}$. The template was amplified by 50 cycles of denaturation for $30 \mathrm{~s}$ at $95^{\circ} \mathrm{C}$, annealing of primers at $60-65^{\circ} \mathrm{C}$ for $30 \mathrm{~s}$ and extension at $72^{\circ} \mathrm{C}$ for $10-20 \mathrm{~s}$. Fluorescence data was acquired during annealing or extension for reactions containing SYBR Green I. Thereafter, PCR products were identified by generating a melting curve. Since the melting curve of a product is sequence specific, it can be used to observe the loss of fluorescence at the denaturation temperature. The melting protocol consisted of heating the samples to $96^{\circ} \mathrm{C}$ followed by cooling to $50^{\circ} \mathrm{C}$ and slow heating at $0.2^{\circ} \mathrm{C} / \mathrm{s}$ to $97^{\circ} \mathrm{C}$ while monitoring fluorescence. The curve was then redrawn as the negative derivative of fluorescence with respect to temperature to generate a melting peak. Test cDNA values were compared with standard cDNA and counted. Primers were used at a concentration of $1 \mu \mathrm{g}$ in each reaction. The RT-PCR parameters followed the protocols of the LightCycler-DNA Master SYBR Green I instrument (Roche). Relative quantities of mRNA were calculated with a known quantity of PCR fragments of $\beta$ crystallin BI and $\beta$-actin using the comparative threshold cycle number of each sample fitted to a five-point standard curve.

Northern blot analysis and wholemount in situ hybridization. Total RNA was isolated from zebrafish at different developmental stages using the guanidinium-phenol-chloroform extraction method (31). Fractions of $10 \mu \mathrm{g}$ of RNA were separated on $1.4 \%$ formaldehyde/MOPS agarose gel, transferred to Hybond $\mathrm{N}+$ nylon membranes (Amersham), and fixed using UV irradiation crosslinking (Stratagene). $\beta$ crystallin B1 PCR fragments (bp 193- bp 597) were radioactively labeled with [ $\left.{ }^{32} \mathrm{P}\right] \mathrm{dCTP}$ (random primer kit, Stratagene) and used as a hybridization probe. Hybridization was carried out overnight at $60^{\circ} \mathrm{C}$. To study the expression of crystalline genes during embryogenic lens development, embryos were fixed and processed for whole-mount in situ hybridization (32). The isolated crystallin cDNAs were used to synthesize sense and antisense RNA probes by using a DIG RNA labeling kit (Boehringer Mannheim). After hybridization at $62^{\circ} \mathrm{C}$, specimens were washed at the same temperature with $0.2 \times \mathrm{SSC}$, and positive signals were detected using a DIG nucleic acid detection kit (Boehringer Mannheim).

\section{RESULTS AND DISCUSSION}

To isolate a full-length cDNA fragment coding the zebrafish $\beta$ crystallin B1 (EMBL Accession No. AJ 317957) protein, RT-PCR amplification of total RNA of eyes was applied using oligonucleotide primers as described under Materials and Methods. A PCR product of approximately 405 bp encoding a truncated CDNA product was cloned into the TOPO vector. Sequencing of the PCR fragments verified that the cloned PCR products encoded the $\beta$ crystallin B1 protein of 


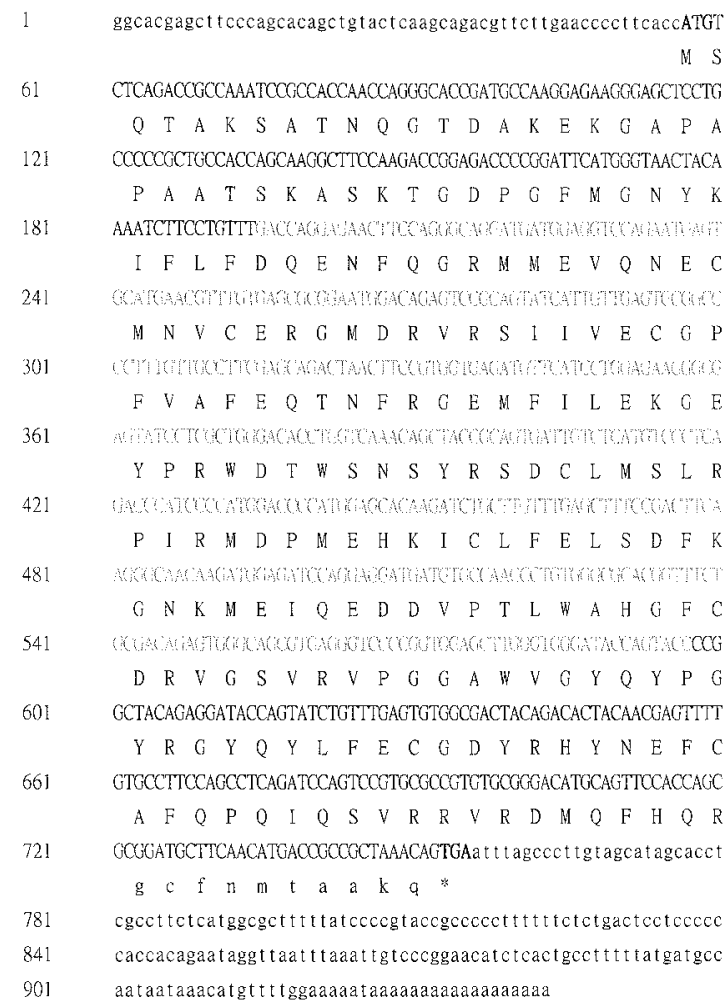

FIG. 1. Nucleotide sequence of $\beta$ crystallin B1 CDNA and deduced aa sequence of the zebrafish $\beta$ crystallin B1 protein (EMBL Accession No. AJ 317957). Uppercase letters in the nucleotide sequence represent the coding region of $699 \mathrm{bp}$; lowercase letters represent the noncoding region. The coding sequence and start and stop codons have been identified by aligning the nucleotide sequence of zebrafish with the known $\beta$ crystallin B1 sequence of chicken, mouse, and human. Numbering of the nucleotide sequence is shown on the left. The start and stop codons are shown in boldface.

zebrafish. Then, using the internal fragment as a probe, we screened about 1 million recombinant bacteriophages from a 48-h zebrafish cDNA library, and finally obtained four positive colonies. The recombinant plasmids of each of these clones were in vivo excised, extracted, and sized by $1 \%$ agarose gel electrophoresis. One of the four clones was chosen for further studies. The size of the cDNA appeared to be about $1 \mathrm{~kb}$ and was identified as zebrafish $\beta$ crystallin B1 by se quencing. The nucleotide sequences were originally cloned into the EcoRI site of the phage ZAP vector. Recombinant DNA was used for sequence analysis of zebrafish $\beta$ crystallin B1 as described in Fig. 1 . The zebrafish $\beta$ crystallin B1 cDNA gene contains 81 bp in 5'UTR and $209 \mathrm{bp}$ in 3'UTR, and the coding region has a length of $699 \mathrm{bp}$. The ATG to TGA domains of the $\beta$ crystallin B1 mature peptide translated into a 233amino-acid residue. A common feature of mRNAs in higher vertebrates is the presence of the sequence AATAAA in the region from 11 to 30 nucleotides upstream of the site of poly $(A)$ addition. A putative polyadenylation signal sequence of AATAAA was found in the 3'UTR (929-934) of zebrafish $\beta$ crystallin B1. These two sites are separated from the above by 10 nucleotides. This indicates that zebrafish possibly uses only one polyadenylation mechanism. Comparison of $\beta$ crystallin B1 amino acids from different animals is shown in Fig. 2. Zebrafish $\beta$ crystallin B1 domains compared to bovine $\beta$ crystallin B1, chicken $\beta$ crystallin $B 1$, rat $\beta$ crystallin B1, bullfrog $\beta$ crystallin B2, and human $\beta$ crystallin B2 domains possess similarities of $71.3,75.9,71.0,66.3$ and $63.9 \%$, and identities of 66.5, $65.9,65.8,56.59$, and $53.7 \%$, respectively. With predicted amino acid sequence comparison between animal species, we inferred that the ancestral $\beta$ crystallin B1 domains have been highly conserved. Comparison of the aa sequences shows that zebrafish $\beta$ crystallin $B 1$ is evolutionarily close to that of the chicken. However, the common feature of $\beta$ crystallin B1 in all animals reported is a proline-alanine (PAPA) sequence in the N-terminus, which is thought to play a role in interaction with cytoskeletal proteins and/or plasma membranes (16). In zebrafish $\beta$ crystallin B1 we have found a proline and alanine-rich sequence in its $\mathrm{N}$ -

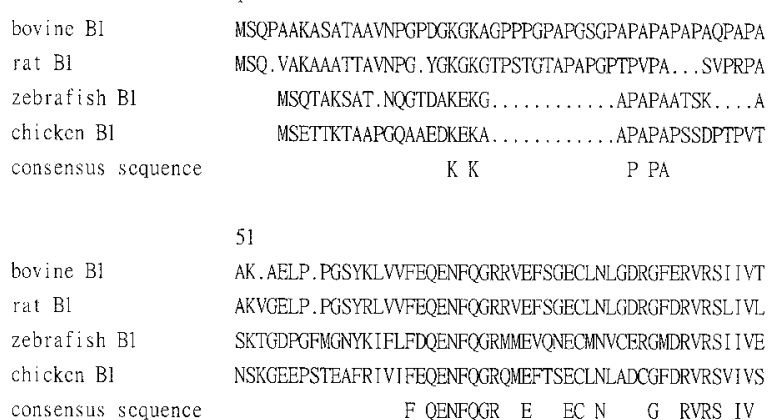

consensus scquence

bovine $\mathrm{B}$ ]

rat B1

zebrafish $\mathrm{B} 1$

chicken $\mathrm{Bl}$

consensus sequence

bovine $\mathrm{BL}$

rat B]

zebrafish $\mathrm{B} 1$

chicken $\mathrm{Bl}$

consensus sequence

bovine $\mathrm{B} 1$

rat B]

zebrafish $B 1$

chicken $\mathrm{Bl}$

consensus sequence
101

SGPWVAFEQSNFRGEMFVLEKGEYPRWDTWSSSYRSDRLMSFRPIKMDAO SGPWVAFEQSAFRGEMFVLEKGEYPRWDTWTSYRSDRLMSFRPIRMDSO CGPFVAFEOTNFRGEMFILEKGEYPRWDTWSNSYRSDCLMSLRPIRMDPM SGPWVAYEQANMRGEMFILEKGEYPRWDTWSSSYRSDCFMSMRPIRMEAE GP VA EQ RGEMF LEKGEYPRWDTW SYRSD MS RPI M

151

EHKLCLFEGANFKGNTMEIOEDDVPSLWYYGCDRVGSVRVSSGTWVYYQ EHK ICLFEGANFKGNTMEIQEDDVPSLWYGFCDRVGSITVSSGTWVGYO EHKICLFELSDFKGNKMEIOEDDVPTLWAHGFCDRVGSVRVPGGAWVYY DHKISLYESADEKGNKMDIOEDDVPSLWAYGFCDRVGSVKVPSGTWVYO HKI L E FKGN M IQEDDVP LW GFCDRVGS V G WVGYQ

201

YPGYRGYOYLLEPGDFRHWNEWGAFOPOMOAVRRLRDROHHREGCFPVLAAEPPK YPGYRGYQYLLEPGDFRHNEWGAFOPOMOAVRLRDROWHOEGCFPVLTAEPPK YPGYRGYYYLFECGDYRIYNEFCAFOPOIOSVRRVRDVOFHORGCFNMTAAKO YPGYRGYOLFETGDFRHWNEWCAFQPQIQSIRRIRDMOWDOKGTFVTPEAPSN

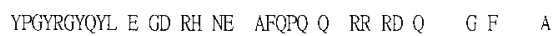

FIG. 2. Amino acid sequence comparison between bovine, rat, chicken, and zebrafish crystalline B1 homologs. The deduced sequence of the zebrafish $\beta$ crystallin B1 protein contains 222 aa. 
A

hrs

hrs

hrs

hrs

hrs

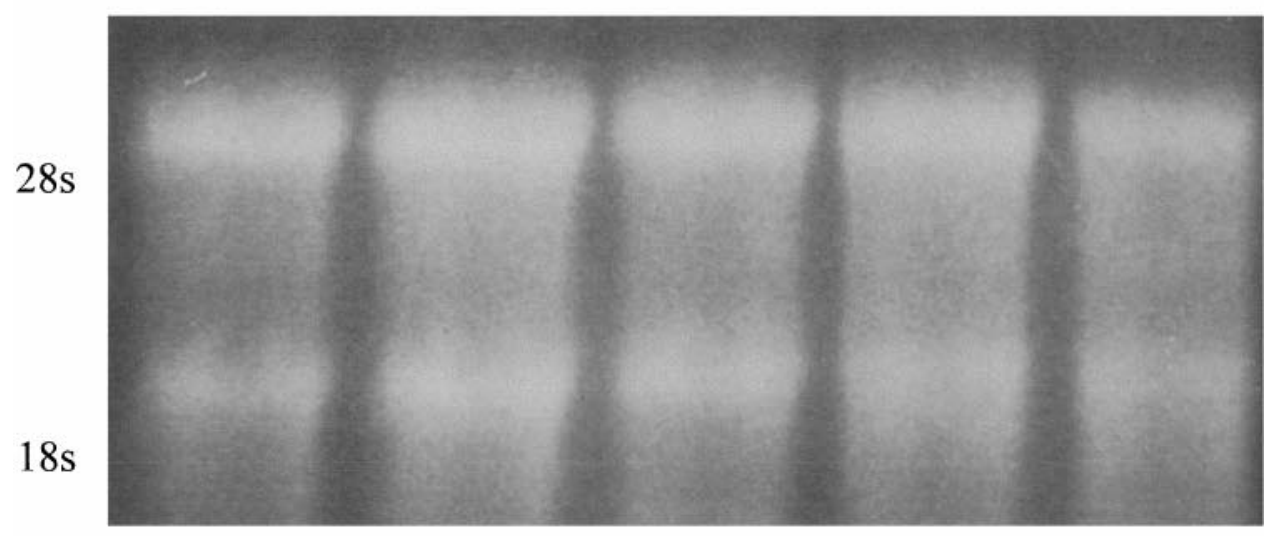

B

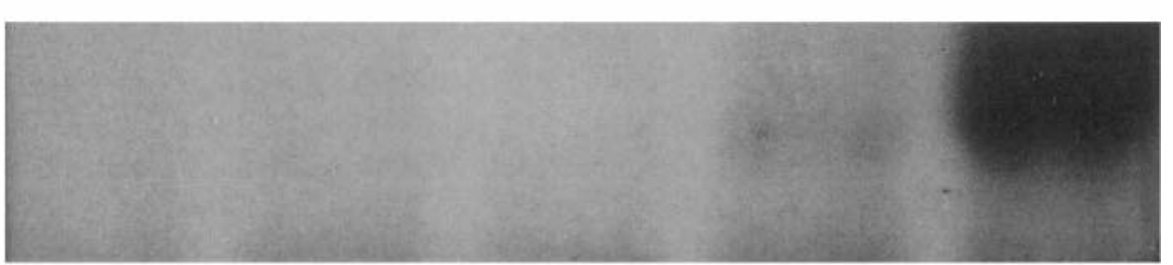

\section{$16 \mathrm{hr}$}
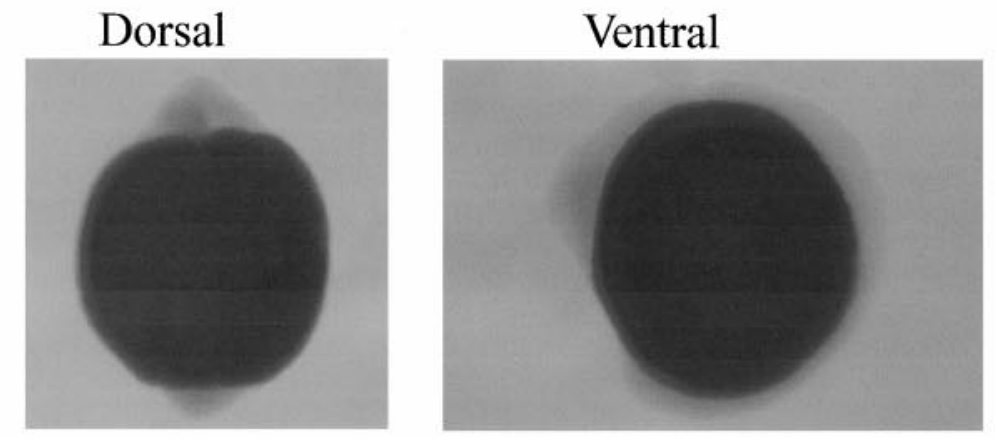

$20 \mathrm{hr}$
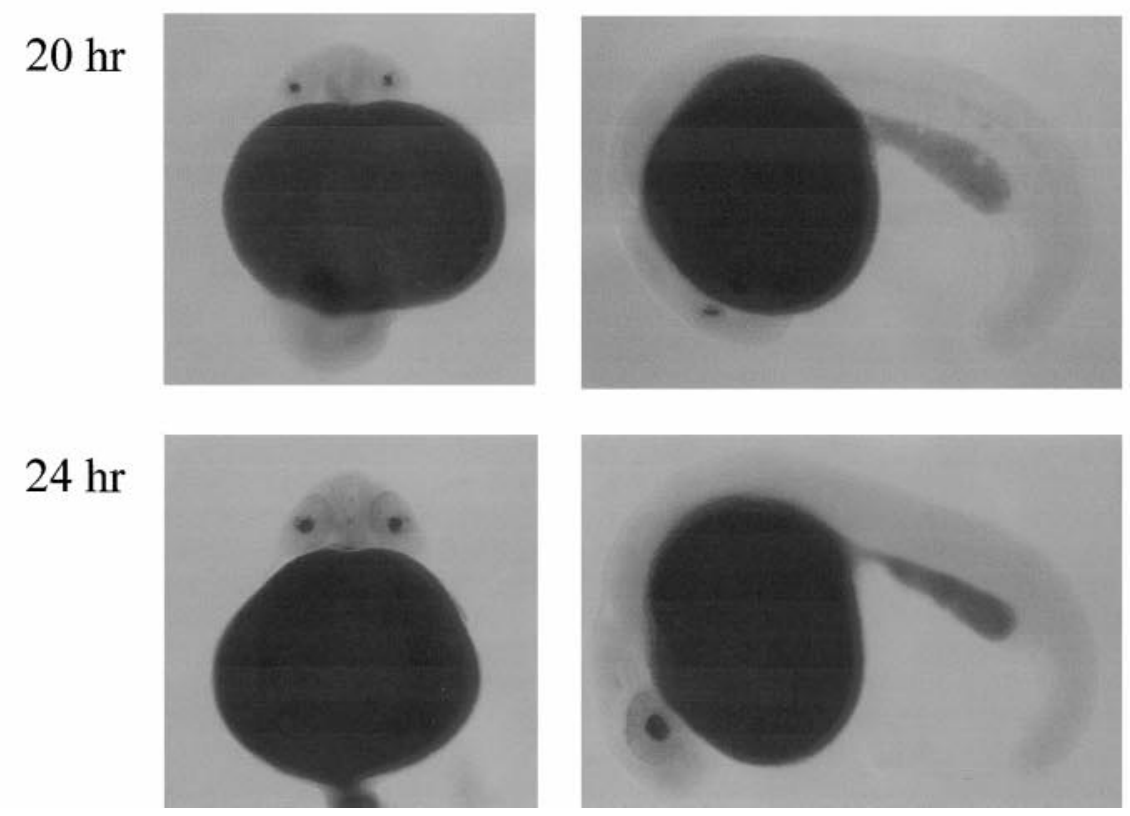

FIG. 3. Expression of zebrafish $\beta$ crystallin B1 transcripts in the embryo stage and specifically in the lens region. (A) Northern blot analysis of $\beta$ crystallin B1 transcripts from embryogenesis stages. Ten micrograms of total RNA isolated from 50 embryos was probed with radioactively labeled PCR-amplified (405 bp) $\beta$ crystallin B1 fragments of zebrafish. 28S and 18S rRNA were used as a loading control. (B) In situ hybridization of $\beta$ crystallin B1 gene expression in the eye region of a zebrafish embryo. On the left is a dorsal view; on the right is the ventral. 
terminus; it does not have the typical PAPA sequence observed in other published animal sequences (17).

Northern blot analysis of total RNA from various embryo stages revealed cross-hybridization with 405-bp (PCR) ${ }^{32} \mathrm{P}$-labeled $\beta$ crystallin B1 fragments, indicating a single $\beta$ crystallin B1 transcript in the embryo stages examined (Fig. 3A). Transcripts were detectable early in embryogenesis at $20 \mathrm{hpf}$ and of the size of $\sim 1 \mathrm{~kb}$ in length. At Xenopus stages 26 to 27 , the $\alpha \mathrm{A}$-crystallin signal was first detected, although faintly, in the central region of the lens placode, while the $\beta$ crystallin B1 signal was first detected in a broad area of the lens placode at stages 26 to 27 (18). Using Northern blot and dot blot analysis of rat after birth, the concentration of $\beta$ crystallin B1 transcripts decreased sharply. The transcripts of $\beta$ crystallin B1 genes were found until the third month after birth. The results suggest that concentrations of the different crystallin mRNAs are thus differentially regulated (19). The time and place of the accumulation of $\beta$ crystallin B1 RNA in the developing zebrafish lens were studied by in situ hybridization (Fig. 3B). In the rat, $\beta$ crystallin B1 RNA could be seen only after elongation of the primary fiber cells. $\beta$ crystallin B1 RNA was confined to fiber cells of fetal lenses, and $\beta$ crystallin B 1 RNA was relatively poorly detectable by in situ hybridization in both fetal and newborn rat lenses. Our re sults in zebrafish show that $\beta$ crystallin B1 RNA begins to accumulate as soon as in 20 phf with specific expression only in the lens region.

To determine the effect of starvation, insulin, IGF-I, IGF-II, and GH on zebrafish $\beta$ crystallin BI RNA expression levels, various concentrations of these growth factors were injected, and tissue was harvested and assayed for the expression of $\beta$ crystallin B1. Data are shown in Fig. 4. There were no significant differences in expression of $\beta$ crystallin B1 mRNA by stage of starvation in zebrafish (Fig. 4A). This proves that the expression of zebrafish $\beta$ crystallin B1 mRNA does not play a role in impaired growth during nutritional restriction in starvation. Our data are demonstrable by the injected effect as shown in Fig. 4B. After injection with IGF-I, IGF-II, or GH, we found that in the first $15 \mathrm{~h}, \beta$ crystallin B1 mRNA had decreased in comparison to the control groups injected with IGF-I or GH, while in fish injected with IGF-II or insulin, it had increased. At $24 \mathrm{~h}$ after injection with IGF-I, IGF-II, or $\mathrm{GH}$, the $\beta$ crystallin B1 mRNA level had specifically incrased. However, it had decreased by $48 \mathrm{~h}$. With injected insulin, $\beta$ crystallin B1 mRNA levels increased after $48 \mathrm{~h}$. This proves that the expressed zebrafish $\beta$ crystallin B1 mRNA is regulated by insulin families. However, central explants from postnatal rats were cultured with concentrations of FGF-2 known to stimulate fiber differentiation or cell proliferation, with and without I GF -I or IGF - II at concentrations ranging from 0 to $1000 \mathrm{ng} / \mathrm{ml}$ (20). IGF-I has been proposed as a
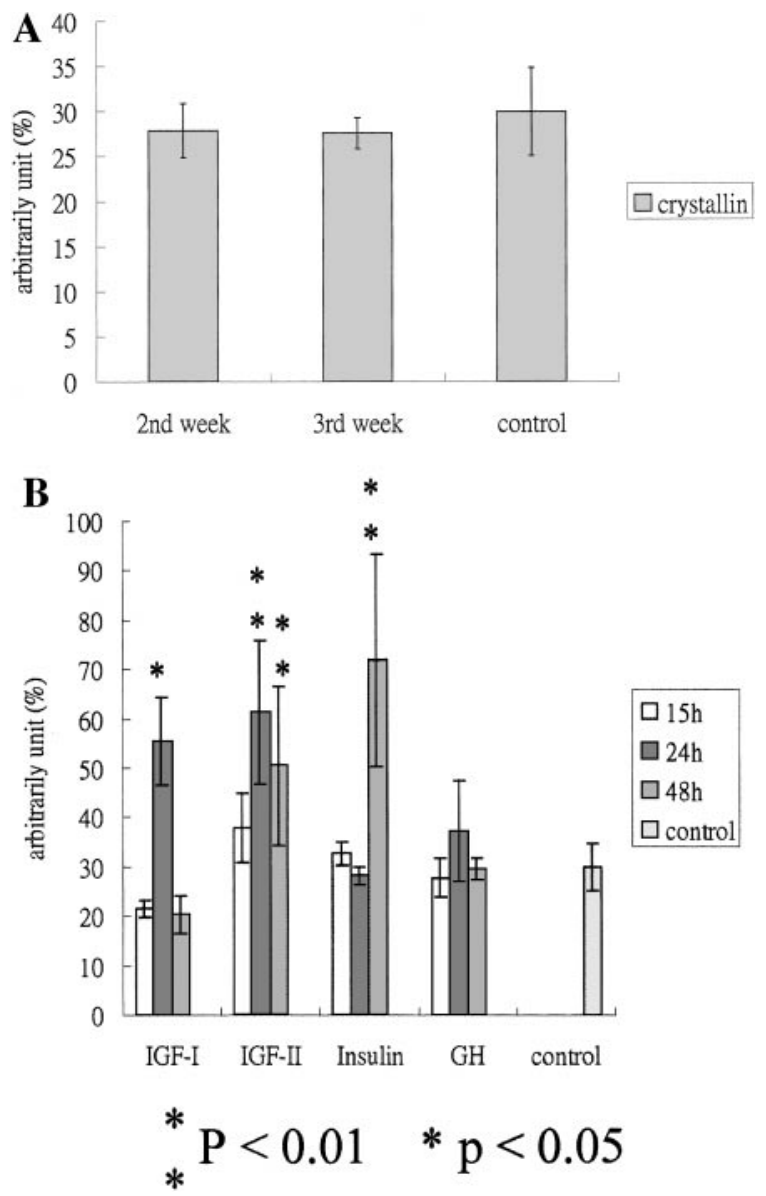

FIG. 4. Real-time quantitative $P C R$ analysis of starvationtreated and hormoneregulated gene expression of $\beta$ crystallin B1. (A) Analysis of $\beta$ crystallin B1 gene expression for different lengths of starvation containing $5 \mu \mathrm{g}$ total RNA from adult zebrafish analyzed by real-time rapid cycle fluorescence PCR as described under Materials and Methods. Measured values represent an arbitrary unit $(\beta$ crystallin B1 PCR value $\times$ ( $\beta$-actin quantitative PCR value $^{-3} \times 100 \%$ ) as defined in Materials and Methods. (B) Analysis of $\beta$ crystallin BI gene expression after injection of pure IGF-I, IGF-II, GH, and insulin or saline with sacrifice of the animals 15, 24, or $48 \mathrm{~h}$ after the injection. Values are the mean \pm SE of three animals. $* p<0.05$ compared with the control.

regulator of lens development. This suggestion arose with the isolation of lentropin, a chick fiber cell differentiation factor identical to IGF-I (21). It has been shown that excess IGF-I does not stimulate premature differentiation of epithelial cells in lens $(22,23)$. In another report using chick epithelial explants, IGF-I was involved in the activity of stimulating fiber cell differentiation (24), whilea different study found al beit modest but similar activity in the rat (10). These data possibly suggest that epithelial differentiation will occur in $\alpha \mathrm{A}-\mathrm{IGF}$-I transgenics (25). It is possible that the apparent discrepancy between mammalian, avian, and fish species might be explained by evolutionary divergence of the different signal transduction pathways for IGF. To determine whether the primary effects of in- 
sulin occur at the level of $\beta$ crystallin B1 mRNA variation, our present findings show that the expression of $\beta$ crystallin B 1 mRNA was found to increase sharply 24 or $48 \mathrm{~h}$ after injection, depending on the different growth factors injected, reaching a steady state level $48 \mathrm{~h}$ later for injected IGF-I (Fig. 4B). The effects of injected insulin reaching a peak level $48 \mathrm{~h}$ later agrees with previous results $(26,27)$. The levels of $\beta$ crystallin B2 increase the concentration of mRNA in the presence of insulin and FGF-2. Given the fact that in a previous study, crystallin mRNAs were shown to be stable, our data suggest that insulin acts to increase the rate or transcription. However, insulin receptors have not yet been reported in rat lens or fish but have been shown to be present in other mammalian (primate lenses) lens cells (28). To integrate all that mentioned above, our results infer that insulin and IGFs may play an important physiological role in the fish lens.

\section{ACKNOWLEDGMENTS}

We thank Dr. Thomas T. Chen for his comments about these experiments and our manuscript. This work was supported by the National Science Council of the Republic of China.

\section{REFERENCES}

1. Fricke, C., Lee, J. S., Geiger-Rudolph, S., Bonhoeffer, F., and Chien, C. B. (2001) Science 292, 507-510.

2. Wistoe, G. J ., and Piatigorsky, J . (1988) Annu. Rev. Biochem. 57, 479-504.

3. Velasco, P. T., Lukas, T. J., Murthy, S. N., Duglas-Tabor, Y., Garland, D. L., and Lorand, L. (1997) Exp. EyeRes. 65, 497-505.

4. Sawada, K., Agata, K., and Eguchi, G. (1992) Exp. Eye Res. 55, 879-887.

5. Nagineni, C. N., and Bhat, S. P. (1992) Exp. Eye Res. 54, 193200.

6. McAvoy, J. W. (1978) J . Embryol. Exp. Morphol. 44, 149-165.

7. Van Leen, R. W., Breuer, M. L., Lubsen, N. H., and Schoenmakers, J. G. (1987) Dev. Biol. 123, 338-345.

8. Stolen, C. M., and Griep, A. E. (2000) Dev. Biol. 217, 205-220.

9. McAvoy, J . W., Chamberlain, C. G., de longh, R. U., Richardson, N. A., and Lovicu, F. J . (1991) Ann. NY Acad. Sci. 638, 256-274.

10. Richardson, N. A., Chamberlain, C. G., and McAvoy, J . W. (1993) Invest. Ophthalmol. Vis. Sci. 34, 3303-3312.
11. Liu, J ., Chamberlain, C. G., and McAvoy, J . W. (1993) Exp. Eye Res. 63, 621- 629.

12. Chen, J . Y., Chang, C. Y., Chen, J . C., Shen, S. C., and Wu, J . L. (1997) DNA Cell Biol. 16, 883-892.

13. Chen, J . Y., Tsai, H. L., Chang, C. Y., Wang, J . I., Shen, S. C., and Wu, J. L. (1998) DNA Cell Biol. 17, 359-376.

14. Chen, J. Y., and Wu, J. L. (1998) J. Fish. Soc. Taiwan 25, 251-263.

15. Chen, J . Y., Chen, J . C., Chang, C. Y., Shen, S. C., Chen, M. S., and Wu, J. L. (2000) Aquaculture 181, 347-360.

16. Hejtmancik, J . F., Thompson, M. A., Wistow, G., and Piatigorsky, J . (1986) J . Biol. Chem. 261, 982-987.

17. Berbers, G. A., Hoekman, W. A., Bloemendal, H., deJ ong, W. W., Kleinschmidt, T., and Braunitzer, G. (1983) FEBS Lett. 161, 225-229.

18. Mizuno, N., Mochii, M., Takahashi, T. C., Eguchi, G., and Okada, T. S. (1999) Differentiation 64, 143-149.

19. Van Leen, R. W., Breuer, M. L., Lubsen, N. H., and Schoenmakers, J. G. (1987) Dev. Biol. 120, 457- 464.

20. Civil, A., van Genesen, S. T., Klok, E. J., and Lubsen, N. H. (2000) Exp. Eye Res. 70, 785-794.

21. Beebe, D. C., Silver, M. H., Belcher, K. S., van Wyk, J. J., Svoboda, M. E., and Zelenka, P. S. (1987) Proc. Natl. Acad. Sci. USA 84, 2327-2330.

22. Lovicu, F. J., and Overbeek, P. A. (1998) Development 125, 3365-3377.

23. Robinson, I. C., Gabrielsson, B., Klaus, G., Mauras, N., Holmberg, C., and Mehls, O. (1995) Acta Paediatr. Suppl. 411, 81- 86.

24. Caldes, T., Alemany, J., Robcis, H. L., and de Pablo, F. (1991) J. Biol. Chem. 266, 20786-20790.

25. Shirke, S., Faber, S. C., Hallem, E., Makarenkova, H. P., Robinson, M. L., Overbeek, P. A., and Lang, R. A. (2001) Mech. Dev. 101, 167-174.

26. Peek, R., McAvoy, J. W., Lubsen, N. H., and Schoenmakers, J. G. G. (1992) Dev. Biol. 152, 152-160.

27. Civil, A., van Genesen, S. T., Klok, E. J., and Lubsen, N. H. (2000) Exp. Eye Res. 70, 785-794.

28. Sinha, A. C., Stuart, C. A., and Srivastava, S. K. (1990) Lens Eye Toxic. Res. 7, 133-141.

29. Schmittgen, T. D., Zakrajsek, B. A., Mills, A. G., Gorn, V., Singer, M. J., and Reed, M. W. (2000) Anal. Biochem. 285, 194-204.

30. Winer, J ., J ung, C. K., Shackel, I., and Williams, P. M. (1999) Anal. Biochem. 270, 41- 49.

31. Chomezynski, P., and Sacchi, N. (1987) Anal. Biochem. 162, 156-159.

32. Hemmati-Brivanlou, A., Frank, D., Bolce, M. E., Brown, B. D., Sive, H. L., and Harland, R. M. (1990) Development 110, 325330. 